\title{
FACES E INTERFACES DO VERBAL E DA IMAGEM NO LIVRO PARA CRIANÇAS E JOVENS
}

\section{FACES AND INTERFACES OF VERBAL AND IMAGE IN ILLUSTRATED BOOKS FOR CHILDREN}

\author{
Maria Zilda DA CUNHA \\ Universidade de São Paulo \\ mariazildacunha@hotmail.com \\ Maria Auxiliadora BASEIO \\ Universidade de Santo Amaro \\ dorafada@ig.com.br
}

Resumo: Estudar a literatura infantil e juvenil implica, entre outros pontos de grande relevância, colocar na pauta das discussões algumas correlações com os diferentes momentos da história dessa produção literária, nos quais entram em cena os aspectos relativos à inserção de ilustrações nos livros de literatura. Assim, sem estabelecer como paradigmática uma forma de arte em relação à outra - seja verbal ou visual - é mister discutir as possibilidades de diálogos que se processam entre a palavra e a imagem no âmbito da cultura livresca. Com essa perspectiva, este artigo aborda algumas das relações que se estabelecem entre essas duas linguagens na Literatura de recepção infantil e juvenil, considerando, nomeadamente, alguns dos desafios impostos pela contemporaneidade. Se essa literatura, em sua gênese, tornou-se reconhecida pela especificidade de sua oralidade e de sua escritura, no decurso da história, foi se entretecendo, no entanto, com as artes visuais e tornando-se um sistema complexo em que se hibridizam códigos e linguagens. A perspectiva metodológica, aqui assumida, fundamenta-se em princípios semióticos, bem como em princípios dos Estudos Comparados de Literatura, horizontes teóricos que orientam o perscrutar dos diálogos que a arte literária estabelece com outras artes, outros saberes e com as demais formas de representação.

Palavras-chave: Imagem. Palavra. Livro ilustrado para crianças e jovens.

\begin{abstract}
The critic studies about Literature for children imply, among other points of great relevance, a large discussion on some correlations with different moments in the history of this production, in which the aspects related to the insertion of illustrations in literature books emerge. Thus, without establishing as paradigmatic one form of art in comparison with other - whether verbal or visual - it is necessary to argue over the possibilities of dialogues that proceed between word and image within the field of book culture. With this perspective, this article approaches some of the dialogues that are established between these two languages in Literature for children, considering, in particular, some of the challenges imposed by contemporaneity. If this literature, in its genesis, became recognized by the specificity of orality ou writing, in the course of

Artigo recebido em 30/10/2016 e aceito em 30/11/2016.
\end{abstract}


History, it was mixed, however, with the visual arts and is becoming a complex system in which codes and languages are hybridized. The methodological perspective assumed here is based on semiotic principles, as well as on principles of Comparative Studies of Literature, theoretical horizons that guide the searching of dialogues that literary art establishes with others arts, other knowledge and with other forms of representation.

Keywords: Verbal. Image. Illustrated books for children.

\section{Introdução}

O livro tem uma tensão interna, tem seu ritmo,
tem a força das palavras e tem,
principalmente, sua beleza. Graça Lima (1999)

É fato que a multiplicação de códigos gerou e continua gerando profundas mutações no mundo da linguagem e isso requer um esforço no sentido de desenvolver uma percepção capaz de sentir e inteligir as operações de interinfluências que uma linguagem pode exercer sobre a outra. Para tal empresa, buscar instrumentais nos princípios dos estudos comparados de literatura e pressupostos semióticos parece-nos importante caminho, quando o que se pretende é estudar a relação da literatura com outras artes e outras formas do saber, o que inevitavelmente implica correlacionar sistemas de signos. Neste artigo, compreendendo a multiplicidade de linguagens em manifestação no livro ilustrado para crianças e jovens, visamos examinar as relações palavras e imagens, como um sistema de linguagens, em que verbal, visual, projeto gráfico e design do próprio livro encenam articulações no engendrar de um objeto de muita complexidade.

\section{A imagem e a capacidade humana de produzir linguagem}

Em seu processo civilizatório, o homem sempre deixou marcas visíveis de suas habilidades imaginativas em forma de desenhos e representações que, desde a antiguidade até a época contemporânea, procuraram comunicar sentimentos - medos, anseios, desejos, aspirações, entre outros -, que experimenta compreender e dominar à medida que os torna visíveis. A imagem pode ser entendida como uma das mais antigas expressões humanas. 
Afrescos, pinturas, iluminuras, ilustrações decorativas, desenhos, gravuras, fotografias, filmes, entre outras formas de linguagens configuram-se como imagens reveladoras de processos de elaboração da experiência, revelando a complexidade da condição humana.

Evidentemente, na singularidade de cada momento histórico, essas representações imaginárias foram tecendo diferentes sentidos. As primeiras inscrições revelavam necessidades de sobrevivência e estreita relação com a vida social. Por demandarem raciocínio e explicações lógicas, apresentavam marcas reveladoras da magia. Tangiam o sagrado. Hoje, dessacralizadas, assinalam para novas formas de compreensão da realidade.

Fato é que, nesta sociedade contemporânea, vivemos bombardeados por imagens, palavras, música, sons e ruídos, vindos de uma gama extensa de mídias audiovisuais, experimentando, via internet e dispositivos móveis, uma comunicação que propicia navegar através da informação a qualquer rincão do planeta. O que, no mundo artesanal, foi denominado suporte, passou, com a revolução eletromecânica, a ser compreendido como meio de comunicação devido ao seu poder de reprodução (BENJAMIN, 1984). A reprodutibilidade dos signos alargou o público receptor e também o poder comunicativo; as mudanças culturais, sociais, econômicas e políticas foram substancialmente se acentuando à medida que passaram a conviver com os meios das novas gerações que emergem com a revolução técnico-eletrônica digital.

As revoluções tecnológicas, no entanto, não podem ser compreendidas apenas como a introdução de uma quantidade de novas mídias. Como assevera Martín-Barbero (2006), essas revoluções abarcam relações bastante complexas entre a constituição do cultural pelos processos simbólicos e as formas de produção e distribuição dos bens e serviços. Trata-se do desenvolvimento de novos modos de percepção de linguagem, além do desenvolvimento de novas sensibilidades, que modificam o estatuto cognitivo, bem como institucional das condições do saber e as figuras da razão, o que conduz "a um forte apagamento de fronteiras entre razão e imaginação, saber e informação, natureza e artifício, arte e ciência, saber experiente e experiência profana" (MARTIN-BARBERO, 2006, p. 54-55). 
Com a invenção da fotografia, registro físico de fragmentos do mundo, desenvolveram-se extensores tecnológicos da capacidade humana de produzir linguagens. Basta lembrar que a Era das imagens de registro físico engendrouse nas artes do movimento e na geração das imagens da realidade virtual, aumentada, misturada, da computação ubíqua etc. A foto, o cinema, o vídeo, a holografia, as recentes imagens virtuais desempenham, sem dúvida, papel relevante de mediadores culturais, sociais e históricos. Importa lembrar que, ao transitarem por essas máquinas semióticas (NÖTH, 2001), os signos multiplicam linguagens e vão criando "um complexo ecossistema comunicativo" (OROZCO, 2006, p. 84, 88). As linguagens, além de crescerem em cada novo veículo, hibridizam-se na convergência dos meios. Se, antes, palavra e imagem misturavam-se com alguma dificuldade, atualmente foto, página, escrita, pintura, diagramação, jornal, livro, tela etc. passaram a conviver em sintaxes híbridas, resultantes da habilidade de manipular a linguagem de uma forma visual e espacial.

\section{Leituras e leitores}

No contexto das discussões que atentam para as novas revoluções tecnológicas e midiáticas, aos educadores agregam-se preocupações acerca da formação do leitor literário e dos livros de literatura destinados à recepção de jovens e crianças. Umas das questões que já esteve em pauta é o nascimento de novas mídias digitais que disputam com o livro a comunicação, o lazer, a oferta de informações e o ambiente de aprendizagem e lúdico das narrativas ficcionais. Evidentemente, sabe-se que as novas tecnologias de comunicação e informação vieram para ficar, no entanto, ressalta-se que, historicamente, a tendência não é a desintegração do suporte anterior, mas é a criação de sistemas interdependentes funcionando de modo que cada meio se alimenta do outro, ao mesmo tempo em que o retroalimenta. A consideração disto é importante, uma vez que teremos de lidar, cada vez mais, com diferentes gerações de meios e linguagens. 
É fato também que, em diferentes momentos históricos, cada sociedade, em função das tecnologias de que dispõe, faz emergir tipos específicos de leitores. Santaella (2004), ao estudar o perfil do leitor contemporâneo, assinala as modificações que marcaram historicamente esses sujeitos. No lluminismo, desenvolve-se um leitor que tinha diante de si textos duráveis (livros) e que podiam ser revisitados a todo e qualquer momento. "Um leitor que contempla e medita. Entre os sentidos, a visão reina soberana, complementada pelo sentido interior da imaginação" (SANTAELLA, 2004, p.24). Esse leitor contemplativo vai tornar-se mais híbrido com a Revolução Industrial, com o desenvolvimento do capitalismo, à medida que os processos de leitura vão implicar um apelo intenso de informações simultâneas. Esse leitor é desafiado à decifração de textos híbridos, um leitor movente, que transita por diferentes mídias, buscando traduzir os códigos e linguagens que cada meio produz, vive em meio à escrita, fotos, publicidades, animações, formas, movimentos etc. Com as atuais estruturas híbridas e seus suportes eletrônicos, com a revolução digital, nesta era de mobilidade, emergem leitores ainda mais híbridos e mutantes imersivos e ubíquos - a navegar em ambientes virtuais. Ao fim e ao cabo, em pleno século XXI, não se podem ignorar os impactos que as dinâmicas históricas desempenham na natureza da própria linguagem, nas formas de leitura, dos sujeitos leitores e nos meios de produção de linguagem, entre os quais está o livro de Literatura para crianças e jovens que até hoje faz reverberar a pergunta aliciana: "de que serve um livro sem figura nem diálogos?"

\section{3. "E de que serve um livro sem figura e sem diálogos?"}

Seguindo algumas pistas históricas, vamos verificar que o público que irá desfrutar os livros infantis e as imagens neles contidas se delineia na época em que a criança deixa de ser misturada ao adulto e uma nova noção de infância passa a contar com a cumplicidade da família e dos ideais da sociedade burguesa (ARIÉS, 1981). A valorização da infância concretiza o 
aparecimento de livros infantis. ${ }^{1}$ Essa noção se desenvolve mais especificamente a partir do século XVIII, mas será com a Revolução Industrial no XIX que o livro para crianças se desenvolve com maior cuidado gráfico e condições econômicas favoráveis para adequada distribuição. Os contos que circulavam oralmente deram origem às primeiras histórias para o público infantil. Os primeiros contos ilustrados foram os provenientes da recolha dos filólogos alemães - os Irmãos Grimm - com desenhos de George Cruickshank (1792 - 1878), quando da primeira tradução para o inglês em 1823.

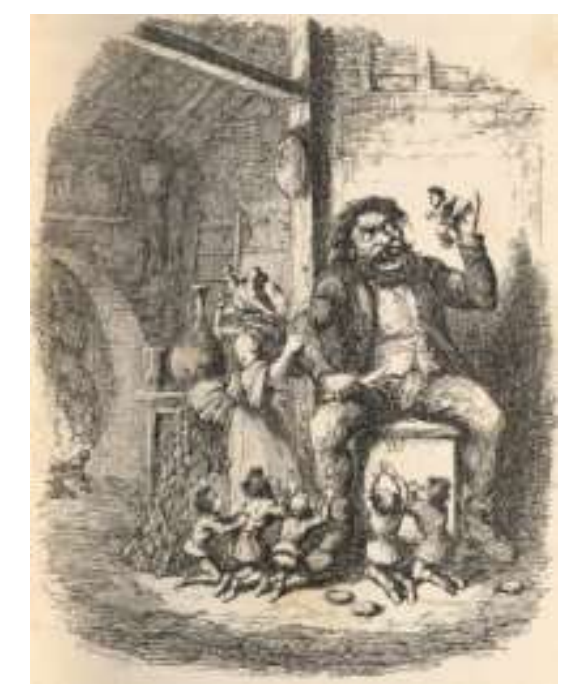

Figura 1: Ilustração de George Cruickshank (1792 - 1878) para contos dos Grimm Foto: Coleção particular

Thomas Bewick (1753-1828), na Inglaterra, inaugura a técnica de xilografia de topo e vai ilustrar diversas dessas narrativas que foram destinadas ao público mais jovem.

\footnotetext{
${ }^{1}$ Se o aparecimento do livro infantil na Europa se dá no período artesanal e pré-industrial $\_$-é apenas com o desenvolvimento da indústria que foi possibilitada a sua impressão e reprodução de imagens nos livros em série, o que coincide com a descoberta da infância nas sociedades de muitos países europeus. Fatos que motivam uma indústria editorial voltada ao público infantil.
} 


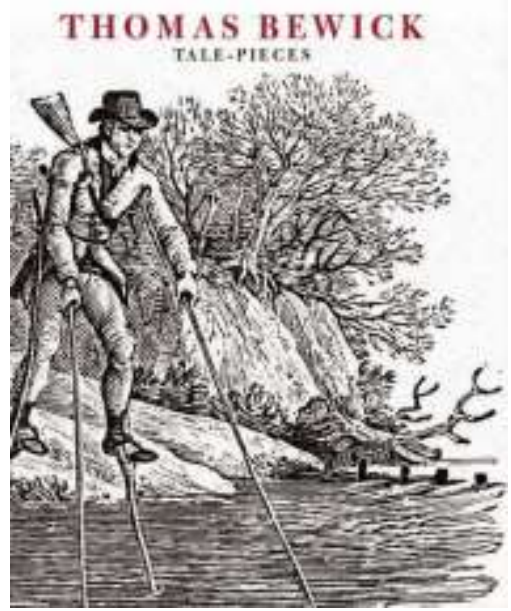

Figura 2: Capa da obra History of British Birds, 1804 Foto: Reprodução

O sucesso foi tanto, que estimulou a publicação de livros ilustrados, na França, de contos de Grimm e Perrault, de fábulas de La Fontaine, agora com gravuras de Gustave Doré. (Fig.3) Doré desenvolve a técnica de gravação por meio de ferramenta ponta-seca com o auxílio de ácido numa placa de cobre. Posteriormente, na Alemanha, foram reeditados os contos de Grimm com ilustrações do alemão Ludvig Richter.

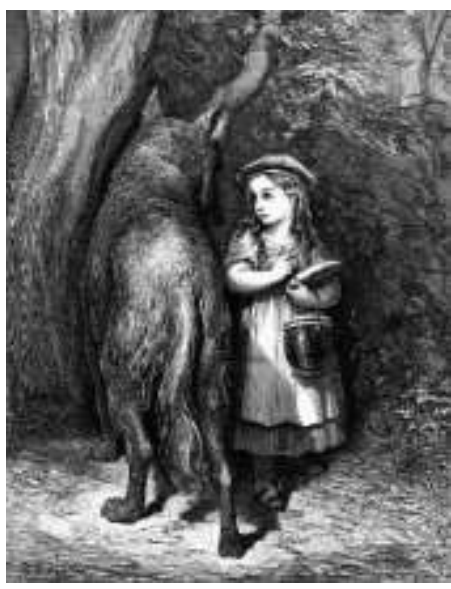

Figura 3: Gravura em metal de Gustave Doré (1833 - 1883) para contos de Perrault

$\mathrm{Na}$ época, cada história apresentava uma imagem como adorno que representava uma cena. Apesar de o campo gráfico ser propício à ilustração, na era vitoriana, verifica-se um número mais expressivo de livros ilustrados para crianças. 


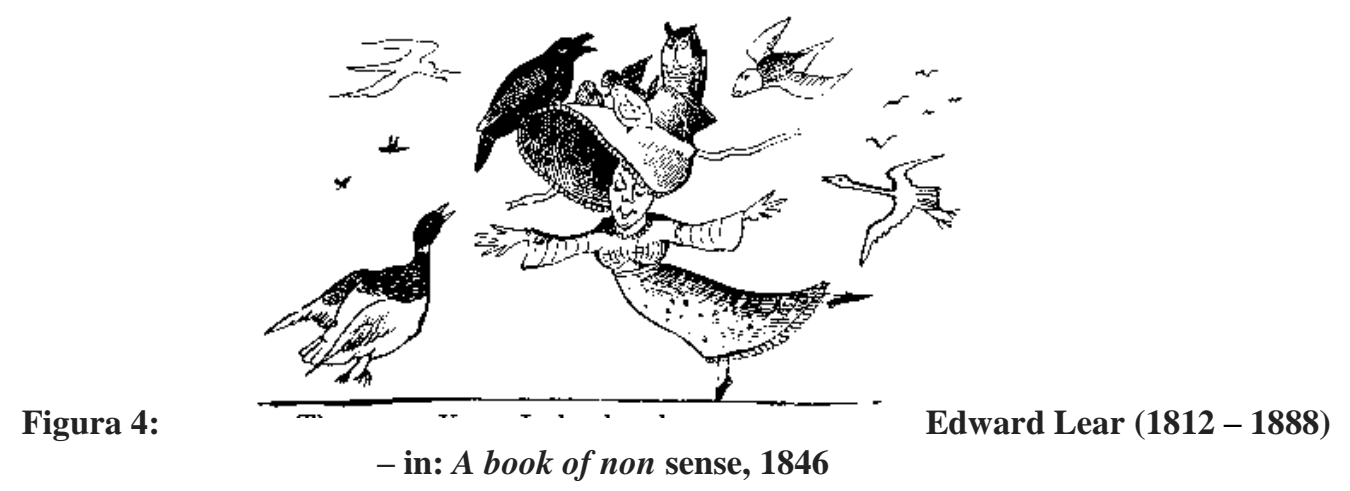

Dentre os ilustradores dessa Era estão Edward Lear (Fig 4); Walter Crane (Fig.5); Arthur Rackham (Fig.6), Tenniel, este, nomeadamente, com as Alices de Carroll.

Figura 5: W. Crane - 1875

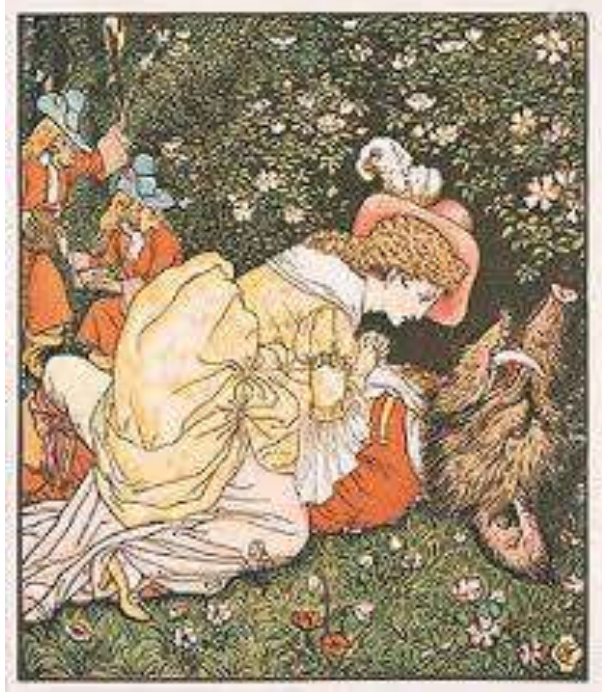

para o conto A Bela e a Fera 


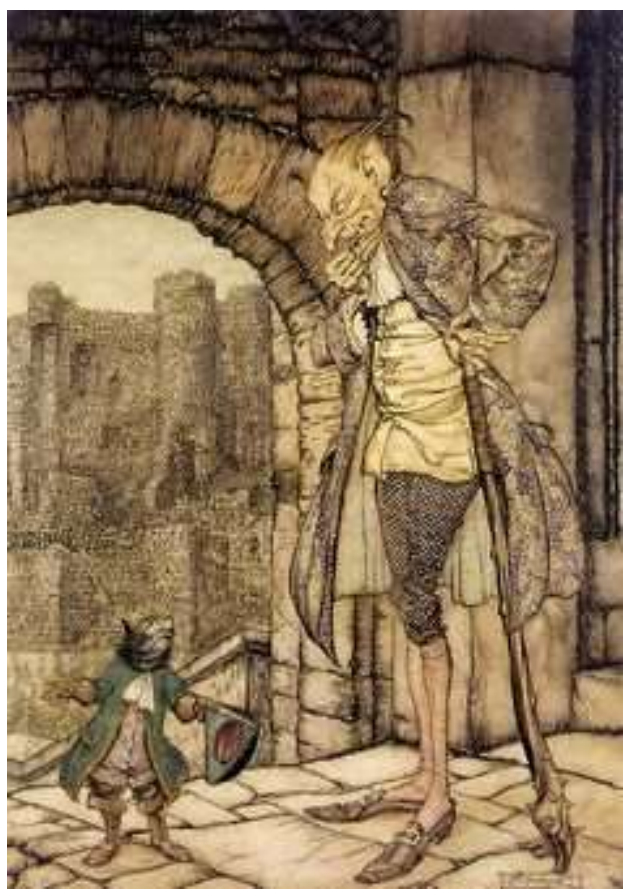

Figura 6: Arthur Rackhman (1867 - 1939) para Gato de Botas Foto: Coleção particular

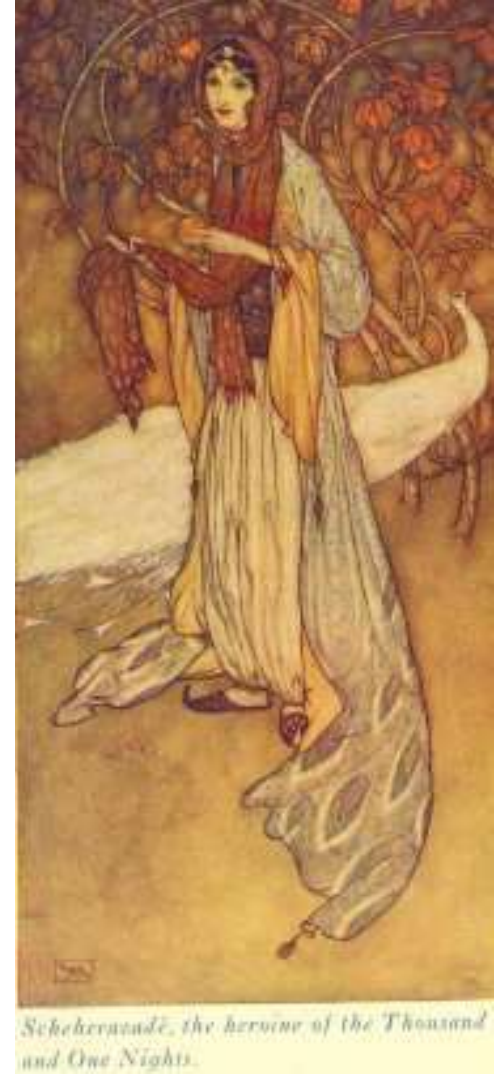

Figura 7: Edmund Dulac (1882 - 1953) para as Mil e uma noites

Se os escritores se dedicavam à escritura das narrativas, os ilustradores preocupavam-se com as imagens para que estas contribuíssem com a educação do olhar. O leitor, assim, lia o escrito e admirava o imagético. Rackhman e Dulac são reflexos dessa postura. Esses livros ilustrados convivem com os de cunho pedagógico e são considerados, na época, objetos estéticos. São muito propícios aos gostos e deleite dos jovens leitores contemplativos que se desenvolviam na época. Leitor "que contempla e medita. Entre os sentidos, a visão reina soberana, complementada pelo sentido interior da imaginação" (SANTAELLA, 2004, p. 24).

\section{As revoluções tecnológicas, a hegemonia da escrita: alguns aspectos e outras considerações}

Com o advento das tecnologias propiciadas pela Revolução Industrial, seguida pela eletroeletrônica, outras modificações ocorreram no mundo das 
linguagens, dos livros e dos leitores. Em primeiro lugar, podemos pensar que, se a invenção da escrita no Oriente manteve a pregnância visual e imagética, como aspectos essenciais para a constituição das escritas ideográficas; no Ocidente, por outro lado, a invenção do alfabeto (o desenho do som) e da sua espetacular maquinaria combinatória faz perder a dimensão de imagem e de plasticidade que subjaz à escrita. A linearidade se impôs na medida em que 0 interesse se voltava prioritariamente para o conteúdo e para a legibilidade do escrito.

Com a invenção da prensa mecânica, a escrita no Ocidente ganha hegemonia. Hegemonia que perdura por um período bastante expressivo na história das linguagens. Vale lembrar, no entanto, que a explosão editorial e a multiplicidade de suportes trouxeram uma intensa variação de tipos gráficos, promovendo forte sincretismo de linguagens e intensificando o diálogo intercódigos, fato que propicia a redescoberta da visibilidade da escrita e sua dimensão plástica. Isto pode ser verificado no ludismo do livro para crianças, que coloca em diálogo faces e interfaces do verbal e da imagem. Basta pensar em Carroll com o poema em forma de rabo em Alice, em que o verbal se iconiza. A imagem ganha estatuto de símbolo no jogo duplo da paronomásia.

Nesse jogo das linguagens, imagem e verbo intercambiam funções. É um contexto em que o livro de Literatura para crianças e jovens torna-se um espaço privilegiado de experimentações de artistas. Angela Lago (1990), de forma muito lúdica, encena, por meio do verbal, inusitados caminhos no livro contemporâneo para crianças no Brasil.

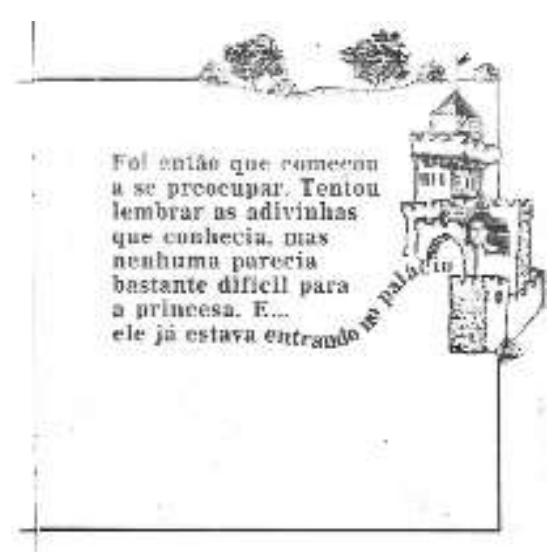

Pensares em Revista, São Gonçalo-RJ, n. 9, p. 45-61, 2016 DOI: $10.12957 /$ pr.2016.30908 
Figura 8: Angela Lago - Sua Alteza A divinha, 1990, RHJ ${ }^{2}$

A leitura desses livros, seguramente, demanda um leitor capaz de entrar no jogo lúdico da linguagem e reconstruir os diálogos entre verbo e imagem para construção de significados.

\section{O livro e o jogo das linguagens}

Heinrich Christian Wilhelm Busch (1832 - 1908), artista alemão, possui um trabalho pictórico que dialoga com as pinturas de Rubens, Brower, Teniers e Frans Hals. Mas ele se torna famoso por suas histórias realizadas com ironia e humor, com textos em verso e ilustradas. Busch é autor de Max und Moritz, narrativa publicada em 1865, na Alemanha, que se torna um clássico. Endereçada ao público infantil, foi traduzida no Brasil e publicada como Juca e Chico pela Editora José Olímpio, no início do século XX. A história narra travessuras de dois garotos, apresentando uma sequência de imagens em continuidade, tal como o cinema viria a tornar conhecido, com os movimentos sequenciais dos fotogramas; seu trabalho é considerado precursor do que seria denominado história em quadrinhos. Tal realização gráfica pode ser considerada também precursora dos livros de imagens ou narrativas de imagem hoje tão apreciados pelas crianças e pelos adultos.

A guisa de exemplo, novamente recorremos a Angela Lago e Outra vez $z^{3}$

\footnotetext{
${ }^{3}$ LAGO, Angela. Outra vez. il. da autora. 7.ed. Belo Horizonte, Miguilim, 1995.
} 


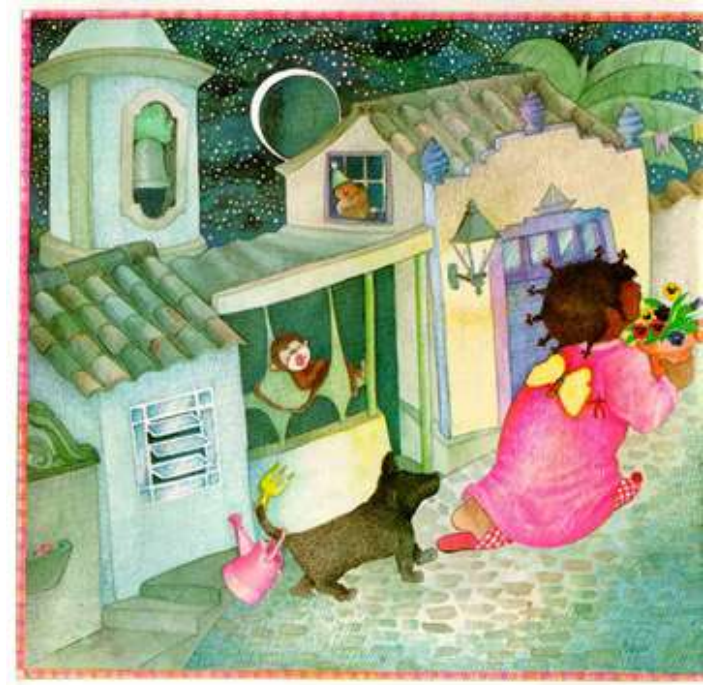

Figura 9: Fonte: Angela Lago, Outra vez, 1995

Obra, cujo tema é o amor, envolve várias histórias: a da menina negra que toma a iniciativa de entregar seu "amor-perfeito" ao menino branco; a do gato aproveitador e ladino pela gata vaidosa; além da fidelidade do cão à garota.

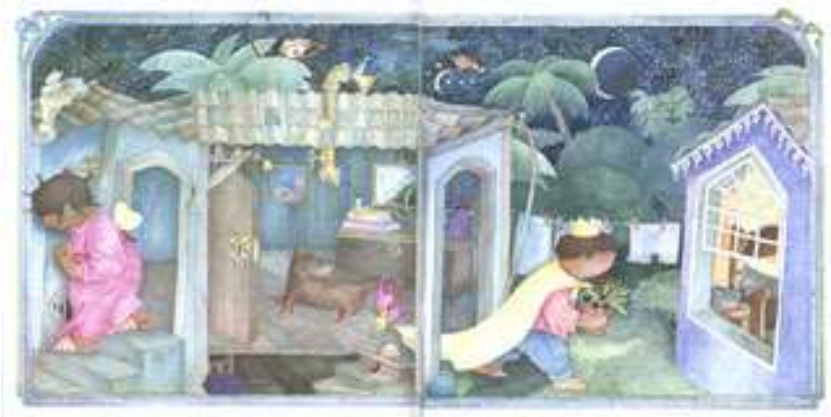

Figura 10: Fonte: Angela Lago, Outra vez, 1995

Outra vez é construída por meio de quadros em páginas duplas, que ampliam a visão e mostram um ambiente extremamente pormenorizado. Tratase de uma narrativa circular, onde o final remete ao início do texto. Assim, a estória termina onde começou. O estilo detalhista de Angela Lago permite-nos, como registrou Luís Camargo (1995), vislumbrar uma típica cidade mineira, com vários elementos de arquitetura e de ornamentação típicos do barroco. As personagens dão a ideia contínua de movimento e dinamismo. A página é aproveitada como recurso de encadeamento e continuidade da ação narrativa. 
O elemento vazado (paredes invisíveis) para o interior das casas permite ao leitor visualizar o encadeamento narrativo, bem como desnuda a permissão do narrador em ampliar/compartilhar o foco narrativo.

Outra vez apresenta complexidade de enredo, entrelaçando vários microeixos narrativos. Há o eixo principal e vários secundários, que sideram e participam da ação principal e a enriquecem. Trata-se de um livro de imagens, mas com palavras compondo as próprias ilustrações - D. Quimera, Royal Crescente, Royal Minguante, Eno, suspiros, sonhos. Os textos intertextualizamse às vistas e com a participação da experiência repertorial do leitor. $O$ tempo/espaço da narrativa é compactuado, compartilhado. É evidente o caráter lúdico do texto. Há um esconde-esconde visual, momentos em que o anjinho desaparece da cena; trocadilhos, o caracol sobe uma escada em caracol, empurrado pela formiguinha; a própria estória faz uma analogia à brincadeira do passa-anel, aqui representada pelo passa-vaso.

Tem-se, na construção desta obra de Lago, recursos pictóricos revelados pela qualidade da pintura que se apresenta como superfície sensível; a invariância ou a organização cromática, o pontilhismo; as leis da geometria; a profusão de detalhes que exige a criação de um tempo mais longo para a fruição/intelecção; a arte sequencial própria das histórias em quadrinhos, a focalização de câmera para construção do ponto de vista, própria da sétima arte.

Seguramente, obras assim construídas demandam a habilidade de um leitor que se torne apto a captar pistas e enlaçar significados. Um leitor movente, desafiado à decifração de textos híbridos, tecido de códigos e linguagens que cada meio produz e que migram para o livro (recursos cinematográficos, de $\mathrm{HQ}$ etc.). As barreiras entre as artes e as mídias se dissolvem, tornando-se permeáveis, os procedimentos estruturantes de cada arte hibridizam-se.

Em a Bela Borboleta de Ziraldo, obra publicada pela Editora Melhoramentos, a estória tem como eixo de construção a metalinguagem e a intertextualidade. É um livro em que o narrador convida ao jogo metalinguístico de sua própria construção: "Era uma vez um livro que começava com uma 
paisagem muito bonita". Mas o virar da página, traz a vinheta de apresentação, com os créditos de autoria e a paisagem muito bonita; algo menos próprio de um livro e mais próximo do momento de apresentação de um filme a ser iniciado. Não apenas misto de verbo e imagem, tem-se aqui o hibridismo pelo código de duas mídias, livro e cinema. O corte cinematográfico e a combinação dos fotogramas encadeiam as ações da narrativa. Os conectores linguísticos que garantem a sintaxe e o fio da narrativa são substituídos por outros no encadeamento dos fotogramas. O narrador reduz a fala e fica em proeminência a linguagem imagética, o que imprime mais movimento para traduzir os pontos de vista. Plano geral e o primeiro plano - close alternam-se e provocam movimento de distanciamento e proximidade do objeto narrado. O próprio livro é explorado como espaço importante da narrativa, suas dobras, sua diagramação encenam o conflito da Bela Borboleta que se encontra presa no grampo do livro. Ao mesmo tempo, a cena remete à liberdade e à relevância dos voos imaginativos.

Reunindo Ciência e Ficção, Cibermãe, como livro de literatura endereçado a jovens leitores, recupera, via representação mimética, a concentração e articulação de processos de linguagens, de estocagem de dados, de vias permutacionais para o acesso à memória, próprios da ambiência computacional. Procedimentos de composição, no cruzar diacronia e sincronia, articulam vozes de passado e presente, tornando-as simultâneas para a construção dos sentidos. Assim, o livro consubstancia-se em espaço lúdico a ser acessado pelo leitor.

Esse leitor age, perceptiva e intelectivamente, como o leitor movente, que emerge no pós Revolução Industrial, aquele que se move por entre pistas e recolhe índices de cada código e linguagem rearticulando-os para 0 processamento de significações, mas, ao mesmo tempo, comporta-se como leitor imersivo (em preparação para os processos de navegação propiciados pela internet), na medida em que deve proceder a uma navegação por entre vias preparadas por esta mídia impressa, que aqui assume caráter hibrido e interativo. 
Esse processo de leitura mobiliza um conjunto de conhecimentos prévios entretecidos na memória da infância - os tempos indefiníveis dos contos de fadas. Desse modo, a obra desperta sensações múltiplas ao cruzar apelo aos sentidos, à memória, à percepção desautomatizada, à imaginação e à intervenção do intelecto. Bela Adormecida ganha, nesta obra, os efeitos visuais e tecnológicos da era digital, dormindo, agora, em um arquivo, possivelmente dentro de uma torre mecânica. A princesa, aqui, transfigura-se virtualmente em mãe. As crianças no contexto da história são obrigadas a passar por uma grande perda, um obstáculo que as mobiliza para a busca.

O texto concentra, além da linguagem verbal, recursos tomados da linguagem tipográfica, da fotográfica, da cinematográfica, da pictórica, e também acena para características da linguagem que derivarão dos processos de digitalização. Sua leitura implica formas intertextuais de acesso, em dialética de renovação. Em vários momentos, intratextualizam-se imagens surreais de Salvador Dali, o 'nonsense' de Lewis Carroll com Alice no país das maravilhas. Um dos aspectos mais inusitados é a revitalização do herói - a máquina neste caso, uma máquina que simula e desafia a inteligência humana, mesmo que artificialmente. No texto de Alexandre Jardin, o herói tem um nome: Ulisses. Percebe-se, portanto, uma personificação da máquina, estabelecendose um laço entre o antigo e o novo. Isso ocorre não só no plano do conteúdo, mas também no plano da forma.

Há imagens da Bela Adormecida que ficam rememoradas dentro da cadeia virtual proposta pela ficção de Alexandre Jardin: o sono, o beijo, o despertar. O sono - semelhante às antigas versões do conto aqui retomado aparece associado à morte, pois é usada a expressão "ajoelhado diante daquele sarcófago eletrônico". Do contador resta um fio de voz que se substancializa em chips. De silêncio a silêncio, compartilha-se de um segredo antigo. Da boca à visão, a palavra se renova. No patamar dos olhos, multiplicam-se, entrecruzam-se, intertextualizam-se experiências vivas.

Enfim, o livro, a diagramação e o leitor interativo, a inteligência astuta, capaz de perseguir pistas são requisitados. É como se, no perfazer da história, o livro, na tessitura de imagem e verbo, contribuísse para as aprendizagens 
necessárias de cada época, para o enfrentamento das revoluções no universo da linguagem e dos meios de produção de linguagem.

\section{A sintaxe múltipla dos labirintos}

Como já comentamos, estamos, em maior ou menor grau, inevitavelmente, nos relacionando com estruturas híbridas, inauguradas pelos suportes eletrônicos e intensificadas pela revolução digital. Nesta Era de mobilidade, os leitores revelam-se cada vez mais híbridos e mutantes imersivos e ubíquos - disponíveis para navegar nos ambientes virtuais. O livro, como uma mídia, cuja materialidade física difere da imaterialidade dos ambientes virtuais, convive intensamente com as demais mídias existentes. A produção contemporânea, livresca ou não, revela-se no conjunto de obras diversas, muitas das quais são concebidas de forma potencial, isto é, pressupondo um trabalho de "finalização" provisória por parte do leitor, ou espectador, ou navegador, ou usuário. Arquitetadas de modo não-linear, compõem-se de textos em fragmentos que estariam ligados, entre si, por elos móveis e probabilísticos. São produções que demandam interatividade, imersão e navegação entre os múltiplos links.

O livro de Roger Mello - Zubair e os labirintos - é obra cujo projeto gráfico é composto de dois livros interligados, um para ser lido da esquerda para a direita em forma de tapete dobrado e o outro é feixe de páginas - para ser lido da direita para a esquerda - dentro desse tapete. Os sentidos da leitura figuram a forma de ler no oriente e no ocidente.

No âmbito da temática, a obra faz referência ao saque ao Museu de Bagdá, durante recente guerra, evidencia-se uma perspectiva crítica a respeito da violência e da guerra, bem como do impacto dessa experiência para a destruição de legados da História e projetos humanos. O artista reveste a realidade brutal, valendo-se de uma complexa trama de linguagens.

A obra diagrama-se de modo a sugerir uma viagem por labirintos. A fragmentação dos múltiplos espaços e a intervenção do passado no presente, através da memória, leva à consciência da instância que narra, ora observador, 
ora imerso na narrativa. Verifica-se: o livro dentro do livro e leitura dentro da leitura. Camadas labirínticas prendem o leitor à história, por meio da escrita, das imagens e do constructo do próprio livro como objeto. O aparecimento do segundo livro traz à tona uma intricada relação de internarratividade. O livro, como um elemento modular interagindo com o todo dentro de uma biblioteca com muitos livros, também é uma biblioteca, na medida em que suas interfaces com outros encadeiam feixe de conexões. A rede de interfaces pela qual se tem acesso a todos os livros retoma uma imagem mítica - a biblioteca da Alexandria -, um centro contendo toda a literatura, as imagens narrativas e 0 conhecimento do mundo. Essa é a ideia do hipertexto.

O leitor em obras assim, opera com um número elevado de interações, o que exige dele interferências, diante de incertezas, indeterminações e de fatores aleatórios. Tal como o texto hipermidiático, este não apresenta uma linha única de raciocínio; ele se abre para a experiência da percepção, da imaginação, do raciocínio do leitor como um processo que se modifica, adaptando-se em relação ao contexto e jogando com dados disponíveis. Segundo Arlindo Machado (2002, p.254), a forma labiríntica da hipermídia repete a forma característica de um chip, ícone por excelência da complexidade em nosso tempo. Uma complexidade que faz da leitura um ato fenomênico, demandando aptidão para apreender signos novos. Um processo de caráter lúdico que vai exigir esforço intelectual, a decisão de querer ou não imergir nesses meandros textuais e uma mente astuta para sondar os enigmas que o livro propõe.

\section{Referências bibliográficas}

ARIÉS, P. História social da criança e da família. 2.ed. Rio de Janeiro: LTC, 1981.

BASEIO, M. A. F. No vaivém da lançadeira:o retorno do sagrado na literatura infantil e juvenil. 2000. (Dissertação (Mestrado em Letras). FFLCH, Universidade de São Paulo, São Paulo. 2000.

BENJAMIN, W. Magia e técnica, arte e política. São Paulo: Brasiliense, 1984.

CAMARGO, L. Ilustração do livro infantil. Belo Horizonte, Lê, 1995. 
CUNHA, M. Z. Na tessitura dos signos contemporâneos: novos olhares para a literatura infantil e juvenil. São Paulo: Humanitas/Paulinas, 2010.

A estética do labirinto na produção para crianças e jovens e os desafios para medir a astúcia do viajante. In: A Literatura infantil e juvenil hoje: múltiplos olhares, diversas leituras. José Nicolau Gregorin Filho, Patricia Kátia da Costa Pina, Regina Silva Michelli (orgs.). Rio de Janeiro: Dialogarts, 2011.

CUNHA, M. Z.; BASEIO, M. A. F. Tecnologias e Literatura para crianças. revista Literartes.v.1 n.1, p. 2012.Disponível em: <http://www.revistas.usp.br/literartes/article/view/47172/50903>. Acesso em: 10 de dezembro de 2016.

JARDIN, A. Cibermãe: uma viagem extraordinária dentro do computador. Trad. Estela dos Santos Abreu. São Paulo: Moderna,1998.

LAGO, A. Sua Alteza A Divinha. Belo Horizonte: RHJ, 1990.

. Outra vez. Belo Horizonte: Miguilim, 1995.

MACHADO, A. Pré -cinema \& pos-cinema.Papirus, 2002.

MARTÍN-BARBERO, J. Tecnicidades, identidades, alteridades: mudanças e opacidades da comunicação no novo século. In: Sociedade Midiatizada. Denis de Moraes (org.). Rio de Janeiro: Mauad, 2006.

MELLO, R. Zubair e os labirintos. Companhia das Letrinhas, 2007.

MORIN, E. Introdução ao pensamento complexo. Lisboa: Instituto Piaget, 1991.

NÖTH, W. Máquinas semióticas. Revista Galáxia, no. 1, 2001.

OROZCO GÓMEZ, G. Comunicação social e mudança tecnológica: um cenário de múltiplos desordenamentos. In: Sociedade Midiatizada. Denis de Moraes (org.). Rio de Janeiro: Mauad, 2016.

SANTAELLA, L. Navegar no ciberespaço: o perfil cognitivo do leitor imersivo. São Paulo: Paulus, 2004.

ZIRALDO. A bela borboleta. São Paulo: Melhoramentos, 1990. 
